\title{
Critical care staffing ratio and outcome of COVID-19 patients requiring intensive care unit admission during the first pandemic wave: a retrospective analysis across Switzerland from the RISC-19-ICU observational cohort
}

\section{Marie-Madlen Jeitziner ( $\square$ Marie-Madlen.Jeitziner@insel.ch )}

Inselspital University Hospital Bern: Inselspital Universitatsspital Bern https://orcid.org/0000-0002-

0275-4602

André Moser

University of Bern: Universitat Bern

Pedro D Wendel-Garcia

University Hospital Zurich: UniversitatsSpital Zurich

Matthias Thomas ExI

Inselspital Universitatsspital Bern Universitatsklinik fur Intensivmedizin

Stefanie Keiser

University Hospital Zurich: UniversitatsSpital Zurich

Reto A Schüpbach

University Hospital Zurich: UniversitatsSpital Zurich

Anne-Aylin Sigg

University Hospital Zurich: UniversitatsSpital Zurich

Urs Pietsch

Kantonsspital St Gallen: Kantonsspital Sankt Gallen

\section{Sara Cereghetti}

Geneva University Hospitals: Hopitaux Universitaires Geneve

Filippo Boroli

Geneva University Hospitals: Hopitaux Universitaires Geneve

Julien Marrel

See-Spital Horgen Branch: See-Spital Standort Horgen

Hatem Ksouri

Fribourg Hospitals: Hopital Fribourgeois

\section{Peter Schott}

Canton of Zug Hospital: Zuger Kantonsspital

Alexander Dullenkopf 
Thurgau Hospital Group: Spital Thurgau AG

\section{Isabelle Fleisch}

Hirslanden Hospital Hirslanden: Hirslanden Klinik Hirslanden

\section{Antje Heise}

Simmental-Thun-Saanenland Hospital Group: Spital STS AG

Jean-Christophe Laurent

Centre Hospitalier Yverdon Chamblon: Etablissements Hospitaliers du Nord Vaudois

\section{Stephan M. Jakob}

Inselspital University Hospital Bern: Inselspital Universitatsspital Bern

\section{Matthias P Hilty}

University Hospital Zurich: UniversitatsSpital Zurich

\section{Yok-Ai Que}

Inselspital University Hospital Bern: Inselspital Universitatsspital Bern

\section{Research}

Keywords: COVID-19, SARS-CoV-2, pandemic, Critical Care, Personnel Staffing, Resource Allocation, patient-to-nurse ratio, patient-to-physician ratio, Mortality

Posted Date: August 31st, 2021

DOI: https://doi.org/10.21203/rs.3.rs-847238/v1

License: (c) (1) This work is licensed under a Creative Commons Attribution 4.0 International License. Read Full License 


\section{Abstract \\ Background}

The modifications to the standard intensive care unit (ICU) organization that had to be urgently implemented worldwide to overcome the surge of ICU admissions due to patients with a severe coronavirus disease 2019 (COVID-19) have resulted in increased workload and patients-to-nurse ratio. The aim of this study was to investigate whether level of critical care staffing could be associated with an increased risk of ICU mortality (primary endpoint), length of stay, mechanical ventilation and the evolution of disease (secondary study endpoints) in critically ill patients with COVID-19.

\section{Methods}

Retrospective multicenter analysis of the international Risk Stratification in COVID-19 patients in the Intensive Care Unit (RISC-19-ICU) registry that prospectively enrolls patients developing critical illness due to COVID-19 in several countries worldwide. The analysis was limited to the period between March 1st, 2020 and May 31st, 2020, to ICUs in Switzerland that have collected additional data on nurse and physician staffing. Hierarchical regression models were used to investigate crude and adjusted effects of critical care staffing ratio on study endpoints. We adjusted for diseases severity and weekly caseload.

\section{Results}

Among the 38 Swiss participating ICUs, 17 recorded critical care staffing information. The study population included 437 patients and 2342 daily assessments of patient-to-nurse/physician ratio. Median of daily patient-to-nurse ratio started at 1.0 ([IQR] 0.5-1.5; calendar week 9) and peaked at 2.4 (IQR 0.4-2.0; calendar week 16), while the median of daily patient-to-physician ratio started at 4.0 (IQR 2.15.0; calendar week 9) and peaked at 6.8 (IQR 6.3-7.3; calendar week 19). Neither the patient-to-nurse ratio [adjusted Odds Ratio (OR) 1.28, 95\% confidence interval (CI) $0.85-1.94$; doubling of ratio] nor the patientto-physician ratio [adjusted OR $1.08,95 \% \mathrm{Cl} 0.87-1.32$; doubling of ratio] was associated with ICU mortality. We found no association of critical care staffing on the investigated secondary study endpoints in adjusted models.

\section{COnclusion}

The Swiss health care system successfully overcame the first wave of the COVID-19 pandemic with regards to the unprecedented demand for ICU treatments. The reduced availability of critical care staffing resources per critically ill patient in Swiss ICUs did not translate in an overall increased risk of mortality.

\section{Introduction}


The rapid spread of the severe acute respiratory syndrome coronavirus 2 (SARS-CoV-2) during the first epidemic wave dramatically stressed healthcare systems in many countries across Europe. In particular, intensive care units (ICUs) were pushed to their limits in terms of critical care staffing resources and bed capacity [1], with some of them being even overwhelmed [2-5]. Patients admitted to the ICU with a severe coronavirus disease 2019 (COVID-19) not only require increased resources [6, 7] but sometimes had to be cared for outside of the regular ICU structure [8-10]. Additional non specialized critical care staff had to be recruited quickly to cope with the increased burden $[11,12]$.

There were major differences in the numbers of patients infected with SARS-CoV2 between regions in Switzerland during the first pandemic wave (March 1st and May 31st 2020) [13]. Southern and Western parts of Switzerland experienced higher SARS-CoV-2 incidence than Centre and Eastern parts, which translated in huge differences in ICU occupancy rates. [14, 15]. With the increasing demand in ICU beds, the standard of the Swiss Society of Intensive Care Medicine regarding personal resource, including required training and staffing per bed [16], could not always be fully satisfied [17].

Before the SARS-CoV-2 pandemic, some studies suggested a relationship between critical care staffing and critically ill patients mortality [18-20]. An increase of either patient-to-nurse ratio or patient-tophysician ratio was associated with worse patient outcomes such as transmission of infections, postoperative complications, including pulmonary failure and reintubation, and increased mortality [2126]. Only few reports evaluated the impact of critical care staffing on ICU mortality during a pandemic [27]. The goal of the present study was to investigate whether the differences in critical care staffing resource allocation as well as caseload observed across Swiss ICUs during the first epidemic wave might have affected COVID-19 patient outcomes.

\section{Methods}

\section{Study Design}

On March 17th, 2020 the prospective observational Risk Stratification in COVID-19 patients in the ICU (RISC-19-ICU) registry was launched to capture COVID-19 features and track characteristics and outcome of patients with SARS-CoV2 infections admitted to ICUs. The registry (ClinicalTrials.gov Identifier: NCT04357275) has been endorsed by the Swiss Society of Intensive Care Medicine (https://www.sgissmi.ch) and was exempt from the need for additional ethics approval and patient informed consent by the ethics committee of the University of Zurich (KEK 2020 - 00322) [1]. The study complies with the Declaration of Helsinki; the Guidelines on Good Clinical Practice (GCP-Directive) issued by the European Medicines Agency as well as the Swiss law and Swiss regulatory authority requirements. The registry has been designed in accordance with the Strengthening the Reporting of Observational Studies in Epidemiology (STROBE) guidelines for observational studies [28]. Eligibility criteria have been described elsewhere $[1,29,30]$. The current retrospective analysis on the RISC-19-ICU registry (KEK 2020 - 00375) incorporated an extended dataset consisting of daily patient-to-nurse and patient-to-physician ratios. The 
analysis is restricted to the period from March 1st 2020 to May 31st 2020, and to participating ICUs across Switzerland.

\section{Patient Data Collection}

A standardized core dataset $[1,29,30]$ was prospectively collected during the ongoing COVID-19 pandemic for all critically ill COVID-19 patients admitted to the collaborating centres. Data collection was performed through an anonymized electronic case report form managed by the REDCap electronic data capture tool hosted on a secure server by the Swiss Society of Intensive Care Medicine. Data were collected on the day of ICU admission, and on days one, two, three, five and seven, including patient characteristics, treatment modalities and organ support therapies, the use of mechanical ventilation, vital parameters, arterial blood gas analyses, and laboratory values such as inflammatory, coagulation, renal, liver and cardiac parameters.

\section{Critical Care Staffing Data}

Patient-to-nurse ratio and patient-to-physician ratio per day were prospectively recorded for patients included in the registry as part of the extended dataset. In those participating centres where resource information had not been collected prospectively, staffing and patient assignment data retrieved from the personnel deployment planning (PEP®), staff planning tool, Dübendorf, Switzerland) and local patient assignment tools was matched with the treated patients. Critical care nursing staff consisted of registered nurses and critical care nurses (registered nurses with a postgraduate in critical care nursing).

\section{Study Outcomes}

Primary endpoint was ICU mortality. Secondary endpoints were ICU length of stay (LOS), mechanical ventilation and evolution of disease as assessed by Sequential Organ Failure Assessment (SOFA) score and C-reactive protein (CRP) levels over time during the ICU stay (see below for the calculation formula).

\section{Data Transformation}

Calculation of the disease severity scores Acute Physiology and Chronic Health Evaluation II (APACHE II), Simplified Acute Physiology Score II (SAPS II) and SOFA scores was performed using an openly available code library associated with the registry [31].

Maximum differences $(\Delta)$ in SOFA and in CRP between days 0 or 1 , and 3 or 5 , were calculated as follows: $\Delta=X \star\left\{\max \left(Y_{3}, Y_{5}\right)-\min \left(Y_{0}, Y_{1}\right)\right\}+(1-X) \star\left\{\min \left(Y_{3}, Y_{5}\right)-\max \left(Y_{0}, Y_{1}\right)\right\}$ where $Y_{d}$ is the measured SOFA, respectively CRP, at day $d \in\{0,1,3,5\}, X=1$ if $\left[\left(Y_{3}+Y_{5}\right) / 2-\left(Y_{0}+Y_{1}\right) / 2\right]>0$, and $X=0$ otherwise.

\section{Statistical Analysis}

We described the study population by counts (n), percentages (\%), mean, median, standard deviation (SD) and interquartile range (IQR). Our main variable of interest was the critical care staffing ratio (daily patient-to-nurse and daily patient-to-physician ratio). For each admission, we calculated the median of the daily 'patient-to-critical-care-staffing' ratio over the ICU stay. 
We used a hierarchical Gaussian regression model to investigate whether the calendar day of ICU admission is associated with the logarithm of 'patient-to-critical-care-staffing' ratio, while accounting for the fact that admissions are nested within hospitals. Calendar day of ICU admission was used as a restricted cubic spline with 3 knots chosen at the 10th, 50th and 90th percentiles [32]. We used a likelihood ratio test to test the non-linear effect of calendar day association on the patient to critical care staffing ratio.

We used multivariable hierarchical regression models to investigate the effect of 'patient-to-critical-carestaffing' ratio on primary and secondary outcomes. We used a hierarchical logistic regression model to investigate the effect of 'patient-to-critical-care-staffing' ratio on ICU mortality, while we used a hierarchical Poisson regression model for LOS [33], a hierarchical Gaussian regression model for $\triangle$ SOFA/ $\triangle \mathrm{CRP}$ and a hierarchical logistic regression model to investigate whether a doubling of the 'patient-tocritical-care-staffing' is associated with the presence of mechanical ventilation. We report crude and adjusted odds ratios (OR), rate ratios (RR) or mean differences (MD) with 95\% confidence intervals (Cls). We a priori defined the following confounding variables: APACHE II and SOFA severity scores, as well as weekly caseload. The 'patient-to-critical-care-staffing' ratio and the weekly caseload was modelled as a linear continuous logarithm-transformed (with respect to basis 2) variable, i.e. the effect on study outcomes is expressed in the doubling of the patient to critical care staffing ratio or the weekly caseload.

\section{Results}

\section{Characteristics of the Study Population}

During the first COVID-19 pandemic wave occurring between March 1st, 2020 and May 31 st 2020 in Switzerland (Supplemental 2 Fig. 1), 38 Swiss ICUs collected data from 669 patients representing a total of 3432 daily assessments (Fig. 1). Among them, 17 ICUs recorded critical care staffing information. After the exclusion of 13 patients with missing survival status, the study population included 17 ICUs, 437 patients and 2342 daily assessments (Fig. 1).

Demographics and comorbidities of critically ill patients included in the study are presented in Table 1. Mean age was 62.6 years (SD 12.3 years) and about three fourths were male. Patients were severely ill with relatively high severity [mean SAPS-II 57.8 (SD 17.3), mean APACHE II 21.2 (SD 6.8), and multiple organ dysfunction scores [mean SOFA score 11.4 (SD 4.5)] th the time of admission. Most (84.9\%) were on mechanical ventilation, and more than half $(55.4 \%)$ were put in prone position sometimes during their ICU stay. Continuous renal replacement therapy was administered in $13.0 \%$ of the critically ill patients. 
Table 1

Patient characteristics and outcomes, by surviving status.

Survivors

$(\mathrm{N}=349)$
Non-survivors

$(\mathrm{N}=88)$
Overall

$(\mathrm{N}=437)$

\section{Gender}

Male

Female

$81(76.8 \%)$

$25(71.6 \%)$

$106(75.7 \%)$

$268(23.2 \%)$

$63(28.4 \%)$

$331(24.3 \%)$

Age

Mean (SD)

$61.0(12.4)$

$68.8(9.63)$

$62.6(12.3)$

SAPS II

Mean (SD)

$55.9(17.5)$

$65.5(14.1)$

$57.8(17.3)$

APACHE II

Mean (SD)

$20.5(6.86)$

$24.1(5.86)$

$21.2(6.82)$

SOFA

Mean (SD)

$11.0(4.40)$

$13.0(4.66)$

$11.4(4.52)$

Median patient to nurse ratio over ICU stay

Mean (SD)

$1.79(0.783)$

$1.91(0.674)$

$1.81(0.765)$

Missing

$80(22.9 \%)$

$27(30.7 \%)$

$107(24.5 \%)$

Median patient to physician ratio over ICU stay

Mean (SD)

$4.02(3.15)$

$4.17(2.98)$

$4.05(3.11)$

Missing

$80(22.9 \%)$

$27(30.7 \%)$

$107(24.5 \%)$

\section{Length of stay in ICU (in days)}

Median (IQR)

$13.0[6.0,22.0]$

$10.5[6.0,22.2]$

$13.0[6.0,22.0]$

Missing

$0(0 \%)$

$2(2.3 \%)$

2 (0.5\%)

\section{Smoking history}

Non smoker

207 (59.3\%)

$46(52.3 \%)$

$253(57.9 \%)$

Past history

90 (25.8\%)

$24(27.3 \%)$

114 (26.1\%)

Notes: SAPS II = Simplified Acute Physiology Score II, APACHE II = Acute Physiology and Chronic Health Evaluation II, SOFA = Sequential Organ Failure Assessment, ICU = Intensive Care Unit, N = Number, SD = Standard Deviation 


\begin{tabular}{|c|c|c|c|}
\hline & Survivors & Non-survivors & Overall \\
\hline Current smoker & $25(7.2 \%)$ & $7(8.0 \%)$ & $32(7.3 \%)$ \\
\hline Missing & 27 (7.7\%) & $11(12.5 \%)$ & $38(8.7 \%)$ \\
\hline \multicolumn{4}{|c|}{ Body mass index $(\mathrm{kg} / \mathrm{m} 2)$} \\
\hline Mean (SD) & $29.1(5.24)$ & $29.0(6.32)$ & $29.1(5.45)$ \\
\hline Median [Min, Max] & $28.0[15.6,50.8]$ & $\begin{array}{l}27.4[19.3 \\
58.4]\end{array}$ & $\begin{array}{l}27.8[15.6 \\
58.4]\end{array}$ \\
\hline Missing & $6(1.7 \%)$ & $11(12.5 \%)$ & $17(3.9 \%)$ \\
\hline \multicolumn{4}{|l|}{ Steroids used } \\
\hline No & $304(87.1 \%)$ & $68(77.3 \%)$ & $372(85.1 \%)$ \\
\hline Yes & $45(12.9 \%)$ & $20(22.7 \%)$ & $65(14.9 \%)$ \\
\hline \multicolumn{4}{|c|}{ Experimental therapy used } \\
\hline No & $184(52.7 \%)$ & $48(54.5 \%)$ & $232(53.1 \%)$ \\
\hline Yes & 165 (47.3\%) & $40(45.5 \%)$ & $205(46.9 \%)$ \\
\hline \multicolumn{4}{|c|}{ Mechanical ventilation } \\
\hline No & $60(17.2 \%)$ & $6(6.8 \%)$ & $66(15.1 \%)$ \\
\hline Yes & $289(82.8 \%)$ & $82(93.2 \%)$ & $371(84.9 \%)$ \\
\hline \multicolumn{4}{|l|}{ Prone positioning } \\
\hline No & $168(48.1 \%)$ & $27(30.7 \%)$ & $195(44.6 \%)$ \\
\hline Yes & $181(51.9 \%)$ & $61(69.3 \%)$ & $242(55.4 \%)$ \\
\hline \multicolumn{4}{|l|}{ ECMO } \\
\hline No & $336(96.3 \%)$ & $78(88.6 \%)$ & $414(94.7 \%)$ \\
\hline Yes & $13(3.7 \%)$ & $10(11.4 \%)$ & $23(5.3 \%)$ \\
\hline \multicolumn{4}{|c|}{$\begin{array}{l}\text { Continuous Renal Replacement Therapy or Hemodialysis of any } \\
\text { form }\end{array}$} \\
\hline No & $308(88.3 \%)$ & $72(81.8 \%)$ & $380(87.0 \%)$ \\
\hline Yes & $41(11.7 \%)$ & $16(18.2 \%)$ & $57(13.0 \%)$ \\
\hline \multicolumn{4}{|c|}{ Chronic arterial hypertension } \\
\hline $\begin{array}{l}\text { Notes: SAPS II = Sim } \\
\text { Health Evaluation II, } \\
\text { Number, SD = Stand }\end{array}$ & $\begin{array}{l}\text { re II, APACHE II = } \\
\text { ilure Assessment }\end{array}$ & $\begin{array}{l}\text { ute Physiology } \\
U=\text { Intensive }\end{array}$ & $\begin{array}{l}\text { d Chronic } \\
\text { Unit, } N=\end{array}$ \\
\hline
\end{tabular}




\begin{tabular}{|c|c|c|c|}
\hline & Survivors & Non-survivors & Overall \\
\hline Not present & $180(51.6 \%)$ & $38(43.2 \%)$ & $218(49.9 \%)$ \\
\hline Present & $169(48.4 \%)$ & $50(56.8 \%)$ & $219(50.1 \%)$ \\
\hline \multicolumn{4}{|c|}{ Ischemic heart disease } \\
\hline Not present & $301(86.2 \%)$ & $69(78.4 \%)$ & $370(84.7 \%)$ \\
\hline Present & $48(13.8 \%)$ & $19(21.6 \%)$ & $67(15.3 \%)$ \\
\hline \multicolumn{4}{|c|}{ Other heart disease } \\
\hline Not present & $310(88.8 \%)$ & 75 (85.2\%) & $385(88.1 \%)$ \\
\hline Present & $39(11.2 \%)$ & $13(14.8 \%)$ & $52(11.9 \%)$ \\
\hline \multicolumn{4}{|c|}{ Diabetes mellitus } \\
\hline Not present & $262(75.1 \%)$ & $60(68.2 \%)$ & $322(73.7 \%)$ \\
\hline Present & $87(24.9 \%)$ & $28(31.8 \%)$ & $115(26.3 \%)$ \\
\hline \multicolumn{4}{|c|}{ Chronic pulmonary disease } \\
\hline Not present & $295(84.5 \%)$ & $73(83.0 \%)$ & $368(84.2 \%)$ \\
\hline Present & $54(15.5 \%)$ & $15(17.0 \%)$ & $69(15.8 \%)$ \\
\hline \multicolumn{4}{|c|}{ Immunosuppression } \\
\hline Not present & $294(84.2 \%)$ & $68(77.3 \%)$ & $362(82.8 \%)$ \\
\hline Present & $55(15.8 \%)$ & $20(22.7 \%)$ & $75(17.2 \%)$ \\
\hline \multicolumn{4}{|c|}{$\begin{array}{l}\text { Notes: SAPS II = Simplified Acute Physiology Score II, APACHE II = Acute Physiology and Chronic } \\
\text { Health Evaluation II, SOFA = Sequential Organ Failure Assessment, ICU = Intensive Care Unit, N = } \\
\text { Number, SD = Standard Deviation }\end{array}$} \\
\hline
\end{tabular}

ICU mortality reached $20.1 \%$ (88 out of 437 ). Survivors had a median LOS of 13.0 days (IQR $6.0-22.0$ days) whereas non survivors had a median LOS of 10.5 days (IQR 6.0-22.2).

The mean $\triangle$ SOFA 0.1 (SD 6.5) and the mean $\triangle$ CRP was 6.8 (SD 159) mg/L, which suggests that no clinically meaningful evolution of inflammation or organ failure occurred during the first 5 days in the ICU.

Characteristics of the patients with known discharge status from those 19 ICUs that did not report staffing had a similar age, gender and ICU mortality distribution [mean age 64.0 (SD 12.8), 74.4\% men, 20.\% ICU deaths), but a less severe disease status [mean SAPS II 44.6 (SD 18.4), mean APACHE II 16.5 (SD 6.9), mean SOFA 9.2 (SD 4.2)], and were less likely to be mechanically ventilated (62.6\%) or to 
received a continuous renal replacement therapy (6.2\%), as compared to the study population (Supplemental 1 Table 2).

\section{'Patient-to-Critical-Care-Staffing' Ratio}

The daily number of critically ill patients hospitalized in the contributing ICUs mirrored the pandemic wave observed in Switzerland over the study period (March 1st - May 31st, 2020, Supplemental 2 Fig. 1). This number increased from 3 (calendar week 9) to 134 (calendar week 13) and decreased thereafter to 1 (calendar week 22). The median of the daily patient-to-nurse ratio started at 1.0 (IQR 0.5-1.5; calendar week 9) and peaked at 2.4 (IQR 0.4-2.0; calendar week 16) (Fig. 2A), while the median of the daily patientto-physician ratio started at 4.0 (IQR 2.1-5.0; calendar week 9) and peaked at 6.8 (IQR 6.3-7.3; calendar week 19) (Fig. 2B).

\section{Effect of Patient-to-Critical-Care-Staffing Ratio on Study Outcomes.}

A doubling of the daily patient-to-nurse ratio did neither influence ICU mortality $\left(\mathrm{OR}_{\text {crude }} 1.35,95 \% \mathrm{Cl} 0.91\right.$ 2.00; $\mathrm{OR}_{\text {adjusted }} 1.28,95 \% \mathrm{Cl} 0.85-1.94$ ) (Fig. 3A), nor any of the secondary study outcomes [LOS (RR crude $1.01,95 \% \mathrm{Cl}(0.97-1.06) ; \mathrm{RR}_{\text {adjusted }} 1.00,95 \% \mathrm{Cl}(0.96-1.04)$ (Fig. 3B), likelihood of being mechanically ventilated $\left(\mathrm{OR}_{\text {crude }} 0.92,95 \% \mathrm{Cl} 0.57-1.50 ; \mathrm{OR}_{\text {adjusted }} 0.78,95 \% \mathrm{Cl} 0.42-1.43\right)$ and $\triangle \mathrm{CRP}\left(\mathrm{MD}_{\text {crude }}-8.4\right.$, 95\% Cl-34.0-17.1, $\mathrm{MD}_{\text {adjusted }}-5.8,95 \% \mathrm{Cl}-31.6-20.0$ ). (Fig. 3C, Fig. 4). Disease evolution as measured by $\triangle$ SOFA showed an association with ICU mortality in crude models ( $\left.\mathrm{MD}_{\text {crude }}-0.97,95 \% \mathrm{Cl}-1.81--0.12\right)$ but not in adjusted models ( $\left.\mathrm{MD}_{\text {adjusted }}-0.23,95 \% \mathrm{Cl}-0.99-0.54\right)$. For patient-to-physician ratio, similar results were obtained (Fig. 5A, B, C, Fig. 6).

\section{Discussion}

It has been hypothesised that reduced critical care staffing and increased workload might have influenced mortality and outcomes in critically ill patients with COVID-19 [14, 18-21, 26, 34]. According to the guidelines of the Swiss Society of Intensive Care Medicine, a critically ill patient requiring controlled mechanical ventilation as well as prone positioning should be cared for by at least three ICU-certified nurses per day [16]. This high quality standard often could not be fulfilled during the first pandemic wave in the participating Swiss ICUs.

We observed a significant increase of both the daily patient-to-nurse and the daily patient-to-physician ratio mirroring the increase in the number of patients. This increase remained modest compared to patient-to-nurse ratio that have commonly been reported worldwide before the pandemic [21, 35], particularly from the USA [34]. Importantly, it did not significantly affect the measured overall outcome of critically ill patients with COVID-19 [36].

Our study is to the best of our knowledge among the first to evaluate the impact of critical care staffing on the outcomes of critically ill patients during a pandemic. There have been reports highlighting the importance of the nurse-to-patient ratio on the quality of critical care [37-39], but most, if not all of them, 
had been performed outside pandemic conditions [6, 27, 40]. Usually, studies compared patient outcomes across ICU centres that are run with different staffing ratio [41,42]. The current particular setting of a pandemic gave us the opportunity to evaluate in addition the effect of critical care staffing changes over time in each single participating centre independently.

Organizational characteristics have been recently shown to affect the outcome of critically ill patients during the COVID-19 pandemic: in a recent study from Belgium, Taccone et al. reported that ICU overflow and the proportion of supplementary beds specially created during the pandemic to care for critically ill patients with COVID-19 were associated with increased in-hospital mortality [43]. Similarly, the US Department of Veteran Affairs Hospital found that strains on critical care capacity - captured by surrogate markers such as the ratio of ICU COVID-19 occupancy to the maximum ICU bed number - were significantly associated with increased COVID-19 ICU mortality [44]. None of these studies investigated patient-to-nurse ratio. However, previous studies reported that better critical care staffing levels as well as higher quality of training of ICU personnel reduced the duration of mechanical ventilation [45]. Also, Hugonnet et al. previously reported an increased risk of late-onset ventilator associated pneumonia by lower patient-to-nurse ratio [46]. Unfortunately, the RISC-19-ICU registry does not collect data to report this outcome.

The increase for nurses and physicians during the pandemic could only be reached by hiring health-care workers without ICU-specific expertise. Thus, the increase in the daily patient-to-nurse and patient-tophysician ratio was linked to a relative decrease in ICU-trained staff. We could have speculated that the reduced specialized care could have contributed to a worse outcome for the most severely ill patients, which our study did however not confirm. Yet, the supervising task for the ICU specialists was dramatically higher. This might explain why healthcare workers from Swiss ICUs have increasingly been reporting anxiety, depression, peri-traumatic distress as well as low well-being [36].

Our study has several strengths that make our observations potentially generalizable. First, the participating centres cover a large spectrum of the existing ICU models of organization: we were able to recruit small low-intensity medical and surgical primary ICUs as well as several large high-intensity interdisciplinary tertiary centres. Second, although all participating ICUs were not equally affected Eastern Switzerland being much less affected than Western and Southern Switzerland - we could find a consistent effect of patient-to-nurse and patients-to-physician ratio on ICU mortality and duration of mechanical ventilation across all ICUs after adjustment for heterogeneity based on caseload.

Our study also suffers from some limitations. The primary endpoint was ICU mortality, as the RISC-19-ICU registry does not collect data on hospital mortality. Second, the data was collected before the publication of the Recovery trial results [47], after which most centres systematically introduced dexamethasone. This may have altered mortality, especially in critically ill patients with high disease severity. Third, not all centres used experimental therapies and we could not exclude a potential bias, as some of these treatments, e.g. chloroquine, have been associated with an increased risk of mortality [48]. Finally, not all Swiss participating ICUs have been collecting data on critical care staffing which might have introduced a 
selection bias. We found that patients from centers which did not record critical care staffing information had a less severe diseases status.

\section{Conclusion}

Our study demonstrates that the Swiss health care system successfully overcame the first wave of the COVID-19 pandemic with regards to the unprecedented demand for ICU treatment. The reduced availability of critically care staffing resources per critically ill patient in Swiss ICUs did neither affect overall ICU LOS nor mortality. Future studies should address the effect of reduced availability of critical care staff on critically ill patients most severely affected by their disease and the mid-term consequences of the augmented workload on healthcare workers health.

\section{Abbreviations}

Acute Physiology and Chronic Health Evaluation II = APACHE II

Confidence interval $=\mathrm{Cl}$

Coronavirus disease $2019=$ COVID-19

C-reactive protein $=\mathrm{CRP}$

Guidelines on Good Clinical Practice $=\mathrm{GCP}=$ Directive

Intensive care units $=$ ICUs

Intensive care unit $=$ ICU

Interquartile ranges $=\mathrm{IQR}$

Length of stay $=$ LOS

Mean difference $=M D$

Odds ratios $=\mathrm{OR}$

Rate ratios $=\mathrm{RR}$

Risk Stratification in COVID-19 patients in the Intensive Care Unit = RISC-19-ICU

Sequential Organ Failure Assessment $=$ SOFA

Simplified Acute Physiology Score II = SAPS ॥

\section{Declarations}


The registry (ClinicalTrials.gov Identifier: NCT04357275) has been endorsed by the Swiss Society of Intensive Care Medicine (https://www.sgi-ssmi.ch) and was exempt from the need for additional ethics approval and patient informed consent by the ethics committee of the University of Zurich (KEK 202000322). The current retrospective analysis on the RISC-19-ICU registry (KEK 2020-00375) incorporated an extended dataset consisting of daily patient-to-nurse and patient-to-physician ratios. All centres have complied with all local legal and ethical requirements.

\section{Consent for publication}

Informed consent for publication was approved by the Ethics committee (KEK 2020-00322, KEK 202000375). All collaborating centers have complied with all local legal and ethical requirements.

\section{Availability of data and materials}

Any intensive care unit or other center treating critically ill COVID-19 patients is invited to join the RISC-19ICU registry at https://www.risc-19-icu.net. While the registry protocol prevents the deposition of the full registry dataset in a third-party repository, analyses on the full dataset may be requested by any collaborating center after approval of the study protocol by the registry board. Reproducibility of the results in the present study was ensured by providing code for registry-specific data transformation and statistical analysis for col- laborative development on the GitHub and Zenodo repositories. The registry protocol and data dictionary is publicly accessible at https://www.risc-19-icu. net.

\section{Competing interests}

The authors declare that they have no competing interests regarding the present study.

\section{Funding}

The RISC-19-ICU registry is supported by the Swiss Society of Intensive Care Medicine and funded by internal resources of the Institute of Intensive Care Medicine, of the University Hospital Zurich and by unrestricted grants from CytoSorbents Europe $\mathrm{GmbH}$ (Berlin, Germany) and Union Bancaire Privée (Zurich, Switzerland). The sponsors had no role in the design of the study, the collection and analysis of the data, or the preparation of the manuscript.

Authors' contributions

MMJ, AM, YAQ, MPH and SMJ conceived and designed this study. PDWG, MTE, SK, RAS, UP, SC, FB, JM, $A A S, H K, P S, A D$, IF, AH and JCL acquired the data. AM and MPH performed data validation, statistical analysis and visualisation. MMJ, MTE, SMJ, MPH and YAQ interpreted the data. YAQ and SMJ drafted the manuscript. MMJ, AM, MPH, PDWG, MTE, SK, RAS, UP, SC, FB, JM, AAS, HK, PS, AD, IF, AH and JCL critically revised the manuscript. MPH had full access to the study data and takes full responsibility for the accuracy of the data analysis. All authors read and approved the final manuscript. 
Acknowledgements

The authors wish to acknowledge all of our collaborators from the RISC-19-ICU Investigators for Switzerland as collaborating authors: Pedro D. Wendel-Garcia, Matthias P. Hilty, Reto A. Schüpbach, Philipp Bühler, Silvio Brugger, Jan Bartussek, Giuliana Capaldo, Sascha David, Stefanie Keiser, Martina Maibach, Annelies Zinkernagel, Mallory Moret-Bochatay, Bernd Yuen, Thomas Hillermann, Hatem Ksouri, Govind Oliver Sridharan, Anette Ristic, Michael Sepulcri, Miodrag Filipovic, Urs Pietsch, Petra Salomon, Iris Drvaric, Peter Schott, Severin Urech, Adriana Lambert, Lukas Merki, Marcus Laube, Frank Hillgaertner, Marianne Sieber, Alexander Dullenkopf, Lina Petersen, Serge Grazioli, Peter C. Rimensberger, Isabelle Fleisch, Jerome Lavanchy, Marie-Helene Perez, Anne-Sylvie Ramelet, Katharina Marquardt, Karim Shaikh, Hermann Redecker, Michael Stephan, Jan Brem, Bjarte Rogdo, Andre Birkenmaier, Friederike Meyer zu Bentrup, Patricia Fodor, Pascal Locher, Martin Siegemund, Nuria Zellweger, Marie-Madlen Jeitziner, Beatrice Jenni-Moser, Jan Wiegand, Christian Bürkle, Gian-Reto Kleger, Marilene Franchitti Laurent, JeanChristophe Laurent, Tomislav Gaspert, Marija Jovic, Michael Studhalter, Christoph Haberthuer, Roger F. Lussman, Daniela Selz, Didier Naon, Andrea Glotta, Samuele Ceruti, Julien Marrel, Mirko Brenni, Rolf Ensner, Marc Michot, Nadine Gehring, Antje Heise, Tobias Huebner, Thomas A. Neff, Sara Cereghetti, Filippo Boroli, Jerome Pugin.

* risc.19.icu@gmail.com

\section{References}

1. Wendel Garcia PD, Fumeaux T, Guerci P, Heuberger DM, Montomoli J, Roche-Campo F, et al. Prognostic factors associated with mortality risk and disease progression in 639 critically ill patients with COVID-19 in Europe: Initial report of the international RISC-19-ICU prospective observational cohort. EClinicalMedicine. 2020;25:100449. https://doi.org/10.1016/j.eclinm.2020.100449.

2. Kleinpell R, Ferraro DM, Maves RC, Kane Gill SL, Branson R, Greenberg S, et al. Coronavirus Disease 2019 Pandemic Measures: Reports From a National Survey of 9,120 ICU Clinicians. Crit Care Med. 2020;48:e846-55. https://doi.org/10.1097/CCM.0000000000004521.

3. Kaplan LJ, Kleinpell R, Maves RC, Doersam JK, Raman R, Ferraro DM. Critical Care Clinician Reports on Coronavirus Disease 2019: Results From a National Survey of 4,875 ICU Providers. Crit Care Explor. 2020;2:e0125. https://doi.org/10.1097/CCE.0000000000000125.

4. Wahlster S, Sharma M, Lewis AK, Patel PV, Hartog CS, Jannotta G, et al. The Coronavirus Disease 2019 Pandemic's Effect on Critical Care Resources and Health-Care Providers. Chest. 2021;159:61933. https://doi.org/10.1016/j.chest.2020.09.070.

5. Vranas KC, Golden SE, Mathews KS, Schutz A, Valley TS, Duggal A, et al. The Influence of the COVID19 Pandemic on ICU Organization, Care Processes, and Frontline Clinician Experiences. Chest 2021:S0012369221010692. https://doi.org/10.1016/j.chest.2021.05.041.

6. Bruyneel A, Gallani M-C, Tack J, d'Hondt A, Canipel S, Franck S, et al. Impact of COVID-19 on nursing time in intensive care units in Belgium. Intensive Crit Care Nurs. 2021;62:102967. 
https://doi.org/10.1016/j.iccn.2020.102967.

7. González-Gil MT, González-Blázquez C, Parro-Moreno Al, Pedraz-Marcos A, Palmar-Santos A, OteroGarcía L, et al. Nurses' perceptions and demands regarding COVID-19 care delivery in critical care units and hospital emergency services. Intensive Crit Care Nurs. 2021;62:102966. https://doi.org/10.1016/j.iccn.2020.102966.

8. Cammarota G, Ragazzoni L, Capuzzi F, Pulvirenti S, De Vita N, Santangelo E, et al. Critical Care Surge Capacity to Respond to the COVID-19 Pandemic in Italy: A Rapid and Affordable Solution in the Novara Hospital. Prehospital Disaster Med. 2020;35:431-3. https://doi.org/10.1017/S1049023X20000692.

9. Lefrant J-Y, Fischer M-O, Potier H, Degryse C, Jaber S, Muller L, et al. A national healthcare response to intensive care bed requirements during the COVID-19 outbreak in France. Anaesth Crit Care Pain Med. 2020;39:709-15. https://doi.org/10.1016/j.accpm.2020.09.007.

10. Drumheller BC, Mareiniss DP, Overberger RC, Sabolick EE. Design and implementation of a temporary emergency department-intensive care unit patient care model during the COVID-19 pandemic surge. J Am Coll Emerg Physicians Open. 2020;1:1255-60. https://doi.org/10.1002/emp2.12323.

11. Villalonga Vadell RM, Sala Blanch X, Roigé Solé J, Garcia Eroles X, Morros Viñoles C, Valero Castell R, et al. Involvement in Catalonia of the Anaesthesiology and Resuscitation Services in the SARS-CoV-2 pandemic. A real, cost-effective solution to an unprecedented health crisis. Rev Esp Anestesiol Reanim Engl Ed. 2021;68:114-6. https://doi.org/10.1016/j.redare.2020.05.016.

12. Uppal A, Silvestri DM, Siegler M, Natsui S, Boudourakis L, Salway RJ, et al Critical Care And Emergency Department Response At The Epicenter Of The COVID-19 Pandemic. New York City's public health system response to COVID-19 included increasing the number of intensive care units, transferring patients between hospitals, and supplementing critical care staff. Health Aff (Millwood). 2020;39:1443-9. https://doi.org/10.1377/hlthaff.2020.00901.

13. Federal Office of Public Helath FOPH. COVID-19 Switzerland. 2021. https://www.covid19.admin.ch. [Accessed July 27th, 2021].

14. Jeitziner M-M, Jenni-Moser B, Yok-Ai Q, Thurnheer Zürcher MC, Furrer H, Jakob SM. Importance of critical care staffing and standard intensive care therapy in the COVID-19 era: a descriptive study of the first epidemic wave at a Swiss tertiary intensive care unit. Swiss Med Wkly. 2021. https://doi.org/10.4414/smw.2021.20529.

15. Primmaz S, Le Terrier C, Suh N, Ventura F, Boroli F, Bendjelid K, et al. Preparedness and Reorganization of Care for Coronavirus Disease 2019 Patients in a Swiss ICU: Characteristics and Outcomes of 129 Patients. Crit Care Explor. 2020;2:e0173. https://doi.org/10.1097/CCE.0000000000000173.

16. Swiss Society of Intensive Care Medicine. Datensatz (MDSi). 2021. https://www.sgissmi.ch/de/datensatz.html. [Accessed July 27th, 2021].

17. Swiss Society of Intensive Care Medicine. 2021. https://www.sgi-ssmi.ch/de/covid19.html. [Accessed July 27th, 2021]. 
18. Aiken LH, Sloane DM, Bruyneel L, Van den Heede K, Griffiths P, Busse R, et al. Nurse staffing and education and hospital mortality in nine European countries: a retrospective observational study. The Lancet. 2014;383:1824-30. https://doi.org/10.1016/S0140-6736(13)62631-8.

19. Needleman J, Buerhaus P, Pankratz VS, Leibson CL, Stevens SR, Harris M. Nurse Staffing and Inpatient Hospital Mortality. N Engl J Med. 2011;364:1037-45. https://doi.org/10.1056/NEJMsa1001025.

20. Rae PJL, Pearce S, Greaves PJ, Dall'Ora C, Griffiths P, Endacott R. Outcomes sensitive to critical care nurse staffing levels: A systematic review. Intensive Crit Care Nurs 2021:103110. https://doi.org/10.1016/j.iccn.2021.103110.

21. Neuraz A, Guérin C, Payet C, Polazzi S, Aubrun F, Dailler F, et al. Patient Mortality Is Associated With Staff Resources and Workload in the ICU: A Multicenter Observational Study*. Crit Care Med. 2015;43:1587-94. https://doi.org/10.1097/CCM.0000000000001015.

22. McHugh MD, Rochman MF, Sloane DM, Berg RA, Mancini ME, Nadkarni VM, et al. Better Nurse Staffing and Nurse Work Environments Associated With Increased Survival of In-Hospital Cardiac Arrest Patients. Med Care. 2016;54:74-80. https://doi.org/10.1097/MLR.0000000000000456.

23. West E, Barron DN, Harrison D, Rafferty AM, Rowan K, Sanderson C. Nurse staffing, medical staffing and mortality in Intensive Care: An observational study. Int J Nurs Stud. 2014;51:781-94. https://doi.org/10.1016/j.ijnurstu.2014.02.007.

24. Aragon Penoyer D. Nurse staffing and patient outcomes in critical care: A concise review. Crit Care Med. 2010;38:1521-8. https://doi.org/10.1097/CCM.0b013e3181e47888.

25. Shekelle PG. Nurse-Patient Ratios as a Patient Safety Strategy: A Systematic Review. Ann Intern Med. 2013;158:404. https://doi.org/10.7326/0003-4819-158-5-201303051-00007.

26. Lasater KB, Sloane DM, McHugh MD, Cimiotti JP, Riman KA, Martin B, et al. Evaluation of hospital nurse-to-patient staffing ratios and sepsis bundles on patient outcomes. Am J Infect Control. 2021;49:868-73. https://doi.org/10.1016/j.ajic.2020.12.002.

27. Xi J, Zeng L, Li S, Ai Y, He X, Kang Y, et al. COVID-19 mortality in ICUs associated with critical care staffing. Burns Trauma. 2021;9:tkab006. https://doi.org/10.1093/burnst/tkab006.

28. von Elm E, Altman DG, Egger M, Pocock SJ, Gøtzsche PC, Vandenbroucke JP. The Strengthening the Reporting of Observational Studies in Epidemiology (STROBE) statement: guidelines for reporting observational studies. The Lancet. 2007;370:1453-7. https://doi.org/10.1016/S01406736(07)61602-X.

29. Hilty MP, Moser A, David S, Wendel Garcia PD, Capaldo G, Keiser S, et al. Near real-time observation reveals increased prevalence of young patients in the ICU during the emerging third SARS-CoV-2 wave in Switzerland. Swiss Med Wkly. 2021. https://doi.org/10.4414/smw.2021.20553.

30. RISC-19-ICU. Investigators W, Garcia PD, Aguirre-Bermeo H, Buehler PK, Alfaro-Farias M, Yuen B, et al. Implications of early respiratory support strategies on disease progression in critical COVID-19: a matched subanalysis of the prospective RISC-19-ICU cohort. Crit Care 2021;25:175. https://doi.org/10.1186/s13054-021-03580-y. 
31. Hobbes8080. hobbes8080/risc-19-icu: Initial code release for basic data transformation. Zenodo. 2020. https://doi.org/10.5281/ZENOD0.3757064.

32. Harrell FE. Regression Modeling Strategies: With Applications to Linear Models, Logistic and Ordinal Regression, and Survival Analysis. Cham: Springer International Publishing; 2015. https://doi.org/10.1007/978-3-319-19425-7.

33. Austin PC, Rothwell DM, Tu JV. A Comparison of Statistical Modeling Strategies for Analyzing Length of Stay after CABG Surgery. Health Serv Outcomes Res Methodol. 2002;3:107-33. https://doi.org/10.1023/A:1024260023851.

34. Lasater KB, Aiken LH, Sloane DM, French R, Martin B, Reneau K, et al. Chronic hospital nurse understaffing meets COVID-19: an observational study. BMJ Qual Saf. 2021;30:639-47. https://doi.org/10.1136/bmjqs-2020-011512.

35. Bakhru RN, McWilliams DJ, Wiebe DJ, Spuhler VJ, Schweickert WD. Intensive Care Unit Structure Variation and Implications for Early Mobilization Practices. An International Survey. Ann Am Thorac Soc. 2016;13:1527-37. https://doi.org/10.1513/AnnalsATS.201601-0780C.

36. Wozniak H, Benzakour L, Moullec G, Buetti N, Nguyen A, Corbaz S, et al. Mental health outcomes of ICU and non-ICU healthcare workers during the COVID-19 outbreak: a cross-sectional study. Ann Intensive Care. 2021;11:106. https://doi.org/10.1186/s13613-021-00900-x.

37. Aiken LH. Hospital Nurse Staffing and Patient Mortality, Nurse Burnout, and Job Dissatisfaction. JAMA 2002;288:1987. https://doi.org/10.1001/jama.288.16.1987.

38. Needleman J, Buerhaus P, Mattke S, Stewart M, Zelevinsky K. Nurse-Staffing Levels and the Quality of Care in Hospitals. N Engl J Med. 2002;346:1715-22. https://doi.org/10.1056/NEJMsa012247.

39. Jha AK, Orav EJ, Zheng J, Epstein AM. Patients' Perception of Hospital Care in the United States. N Engl J Med. 2008;359:1921-31. https://doi.org/10.1056/NEJMsa0804116.

40. Bergman L, Falk A, Wolf A, Larsson I. Registered nurses' experiences of working in the intensive care unit during the COVID -19 pandemic. Nurs Crit Care 2021:nicc.12649. https://doi.org/10.1111/nicc.12649.

41. Aiken LH, Sermeus W, Van den Heede K, Sloane DM, Busse R, McKee M, et al. Patient safety, satisfaction, and quality of hospital care: cross sectional surveys of nurses and patients in 12 countries in Europe and the United States. BMJ. 2012;344:e1717-7. https://doi.org/10.1136/bmj.e1717.

42. Griffiths P, Ball J, Drennan J, Dall'Ora C, Jones J, Maruotti A, et al. Nurse staffing and patient outcomes: Strengths and limitations of the evidence to inform policy and practice. A review and discussion paper based on evidence reviewed for the National Institute for Health and Care Excellence Safe Staffing guideline development. Int J Nurs Stud 2016;63:213-25. https://doi.org/10.1016/j.ijnurstu.2016.03.012.

43. Taccone FS, Goethem NV, De Pauw R, Van Beckhoven D, Meyfroidt G, Blot K. Organizational characteristics: Effect on outcome of ICU COVID-19 patients in Belgium - Authors' reply. Lancet Reg Health - Eur. 2021;3:100070. https://doi.org/10.1016/j.lanepe.2021.100070. 
44. Bravata DM, Perkins AJ, Myers LJ, Arling G, Zhang Y, Zillich AJ, et al. Association of Intensive Care Unit Patient Load and Demand With Mortality Rates in US Department of Veterans Affairs Hospitals During the COVID-19 Pandemic. JAMA Netw Open. 2021;4:e2034266. https://doi.org/10.1001/jamanetworkopen.2020.34266.

45. Blackwood B, Alderdice F, Burns K, Cardwell C, Lavery G, O'Halloran P. Use of weaning protocols for reducing duration of mechanical ventilation in critically ill adult patients: Cochrane systematic review and meta-analysis. BMJ. 2011;342:c7237-7. https://doi.org/10.1136/bmj.c7237.

46. Hugonnet S, Uçkay I, Pittet D. Staffing level: a determinant of late-onset ventilator-associated pneumonia. Crit Care. 2007;11:R80. https://doi.org/10.1186/cc5974.

47. The RECOVERY Collaborative Group. Dexamethasone in Hospitalized Patients with Covid-19. N Engl J Med. 2021;384:693-704. https://doi.org/10.1056/NEJMoa2021436.

48. Axfors C, Schmitt AM, Janiaud P, van't Hooft J, Abd-Elsalam S, Abdo EF, et al. Mortality outcomes with hydroxychloroquine and chloroquine in COVID-19 from an international collaborative metaanalysis of randomized trials. Nat Commun. 2021;12:2349. https://doi.org/10.1038/s41467-02122446-z.

\section{Figures}




38 Contributing Swiss ICUs
$n=669$ patients
$n=3432$ daily assessments

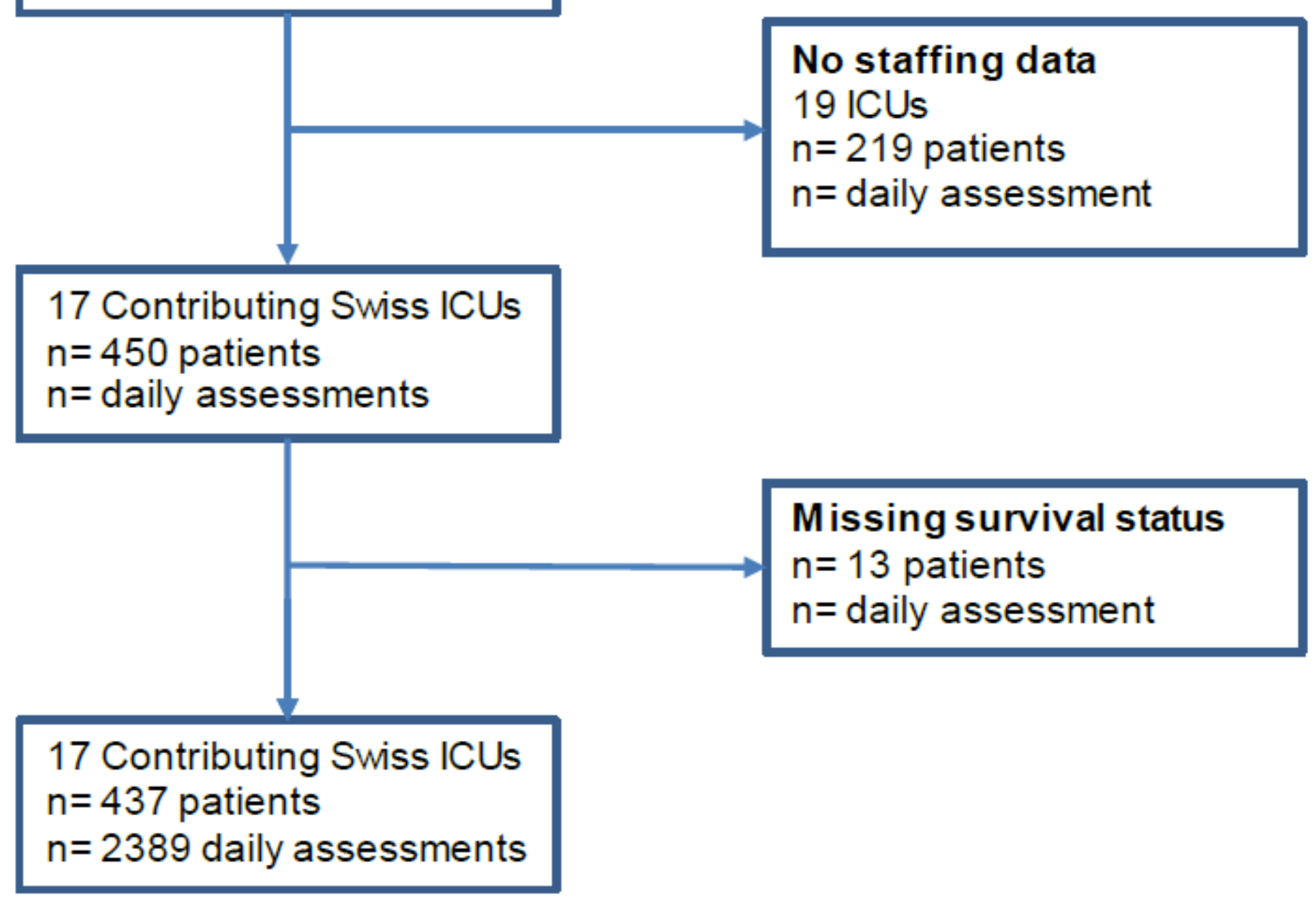

Figure 1

Study Flow Chart. Between during the first epidemic wave Notes: ICU $=$ Intensive Care Unit, $\mathrm{n}=$ number 


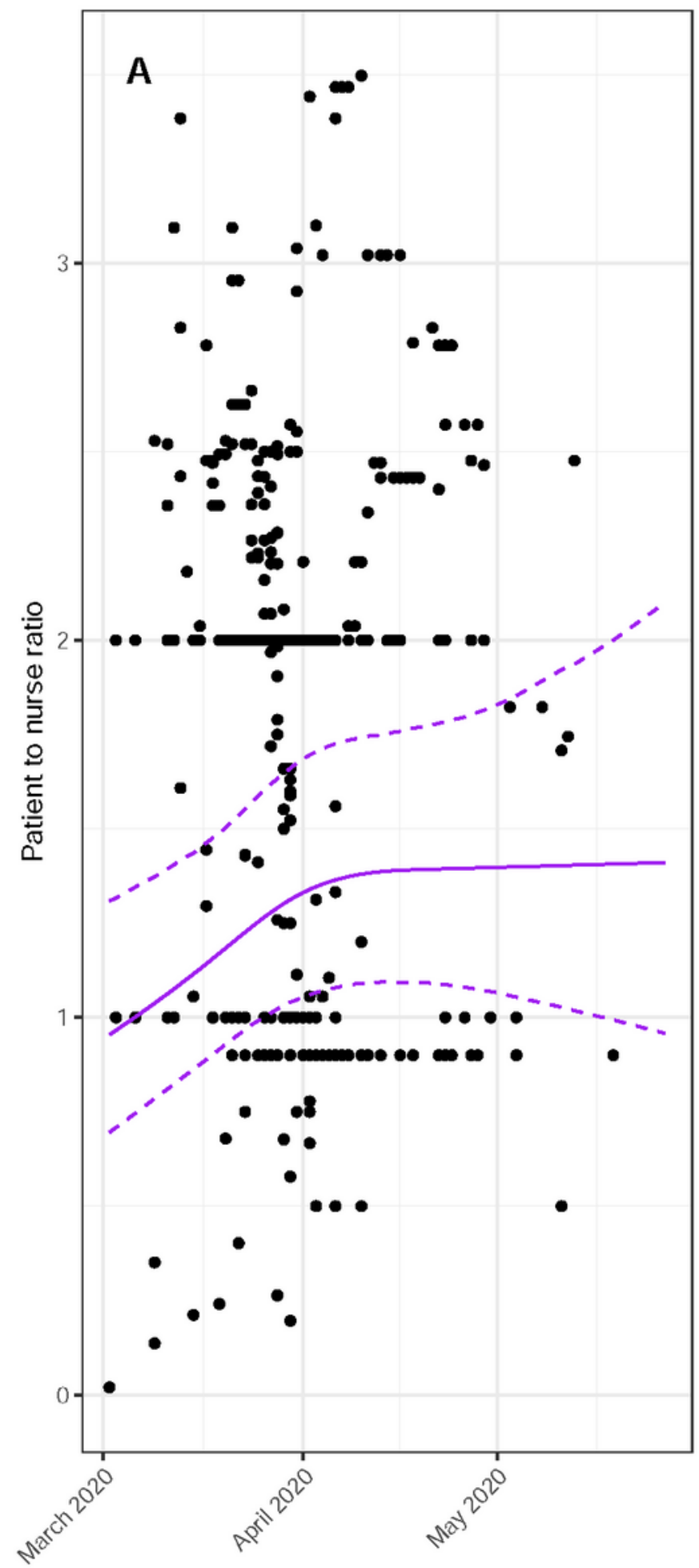

Date of ICU admission

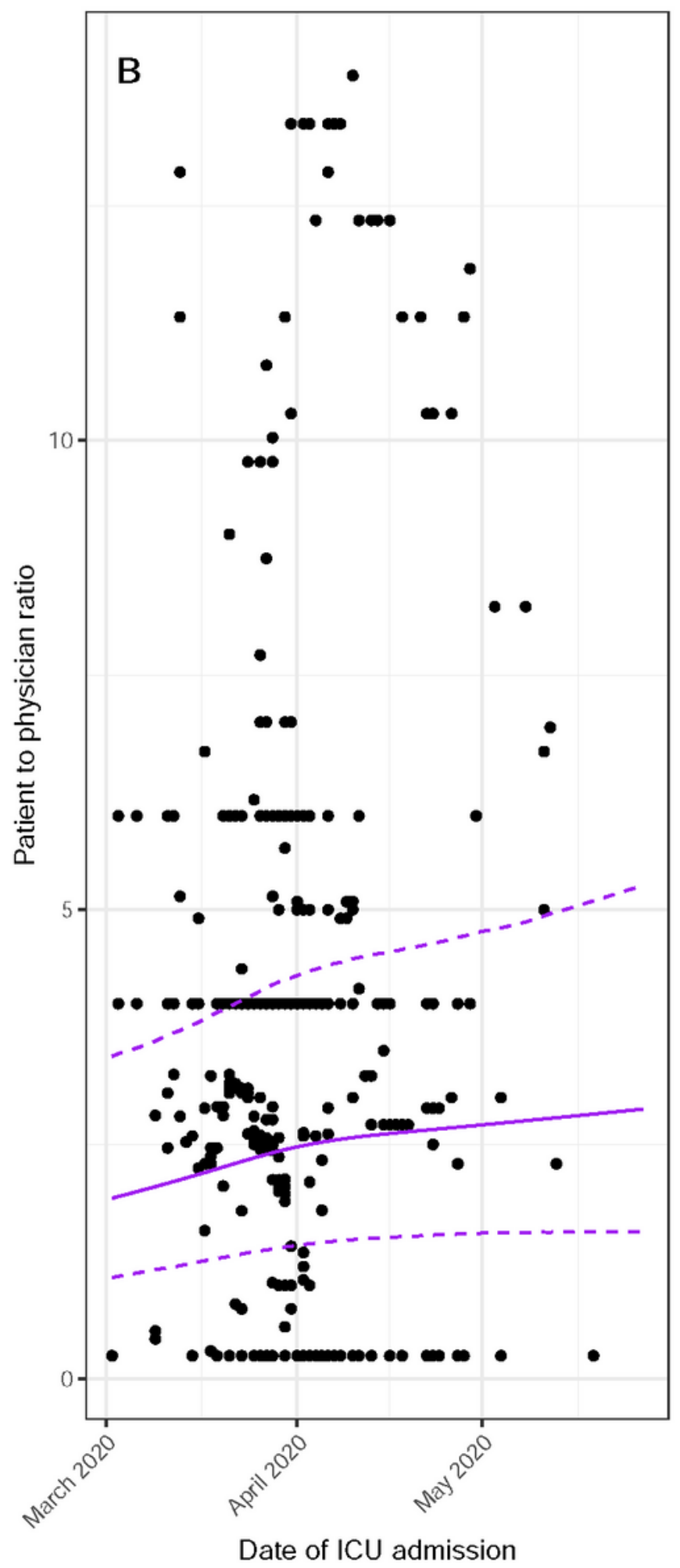

Figure 2

A, B. Patient-to-Critical-Care-Staffing' Ratio Notes: ICU = Intensive Care Unit 

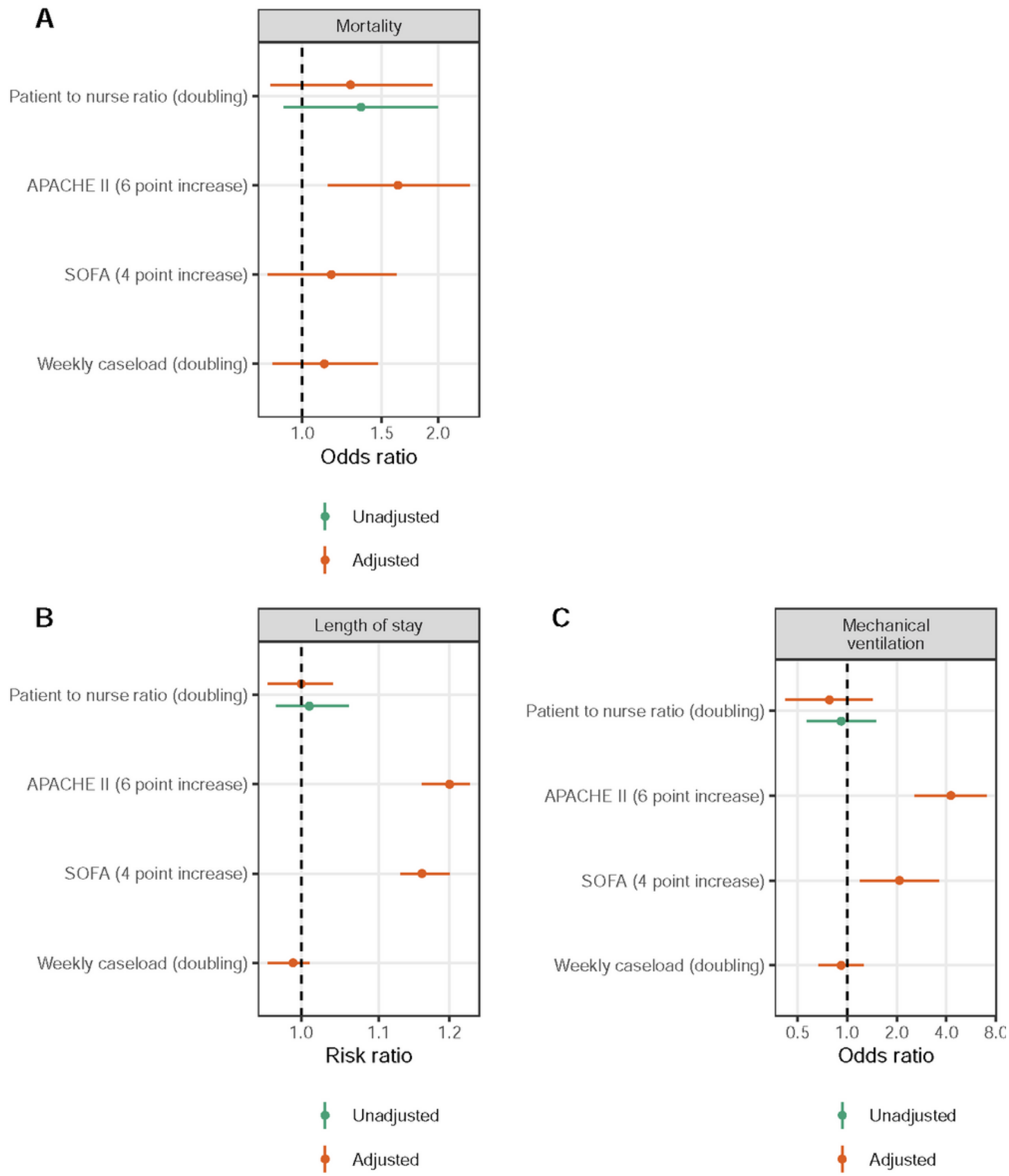

Figure 3

A, B, C. Patient-to-nurse ratio and Study Outcomes Notes: APACHE II = Acute Physiology and Chronic Health Evaluation II, SOFA = Sequential Organ Failure Assessment 


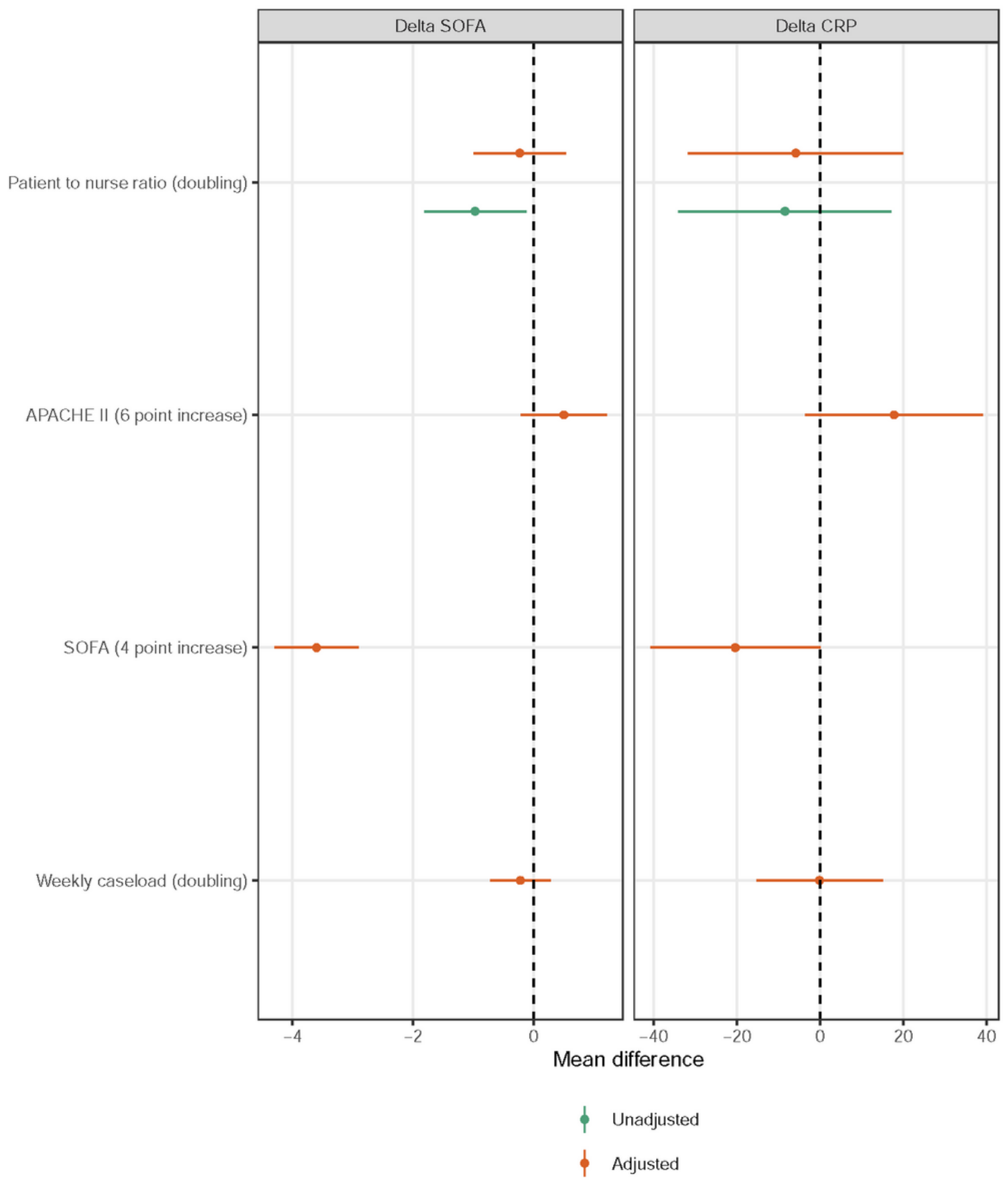

Figure 4

Patient-to-nurse ratio and Delta SOFA, Delta CRP Notes: APACHE II = Acute Physiology and Chronic Health Evaluation II, SOFA = Sequential Organ Failure Assessment, CRP = C-reactive protein 

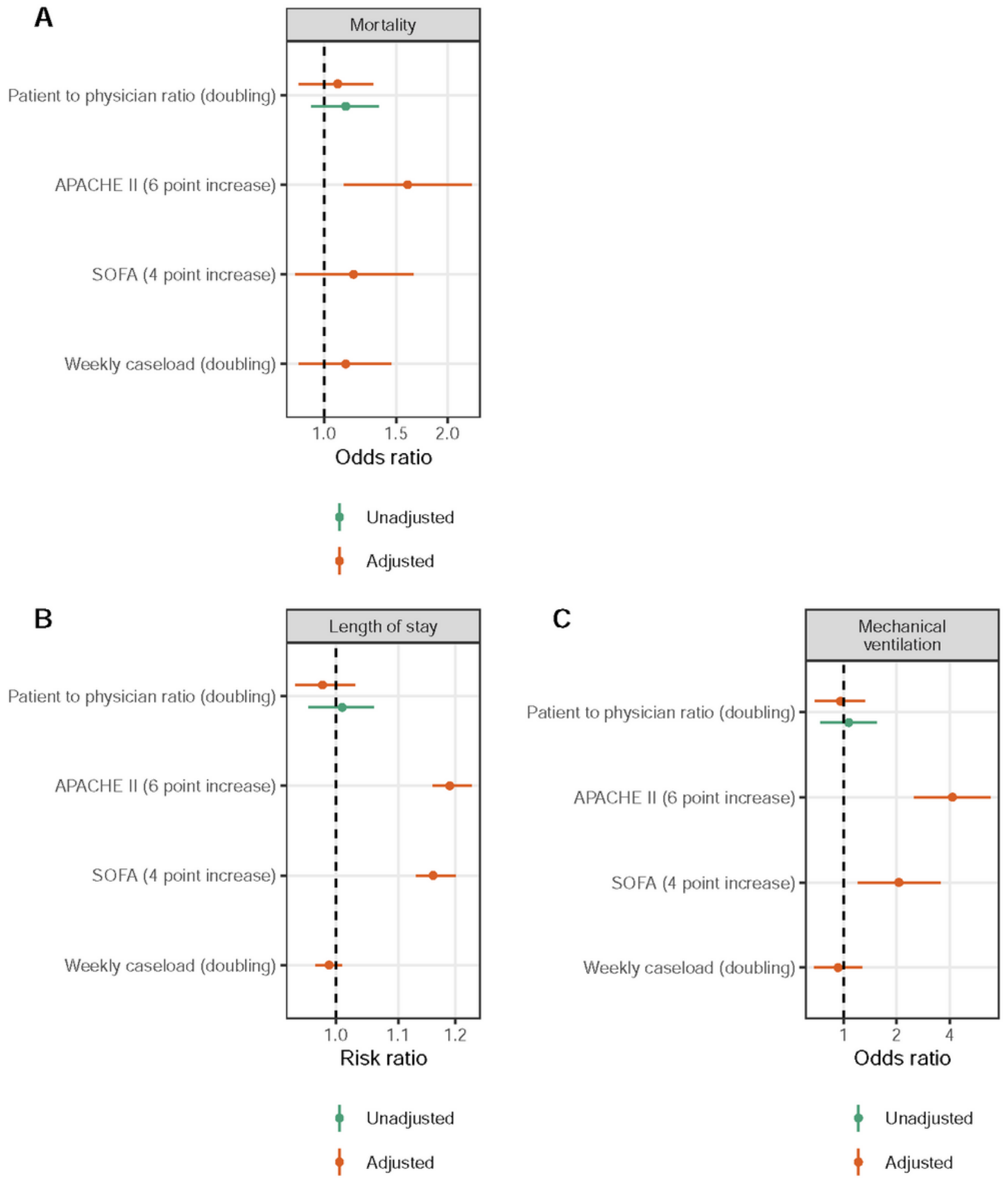

\section{Figure 5}

A, B, C. Patient-to-physician ratio and Study Outcomes Notes: APACHE II = Acute Physiology and Chronic Health Evaluation II, SOFA = Sequential Organ Failure Assessment 


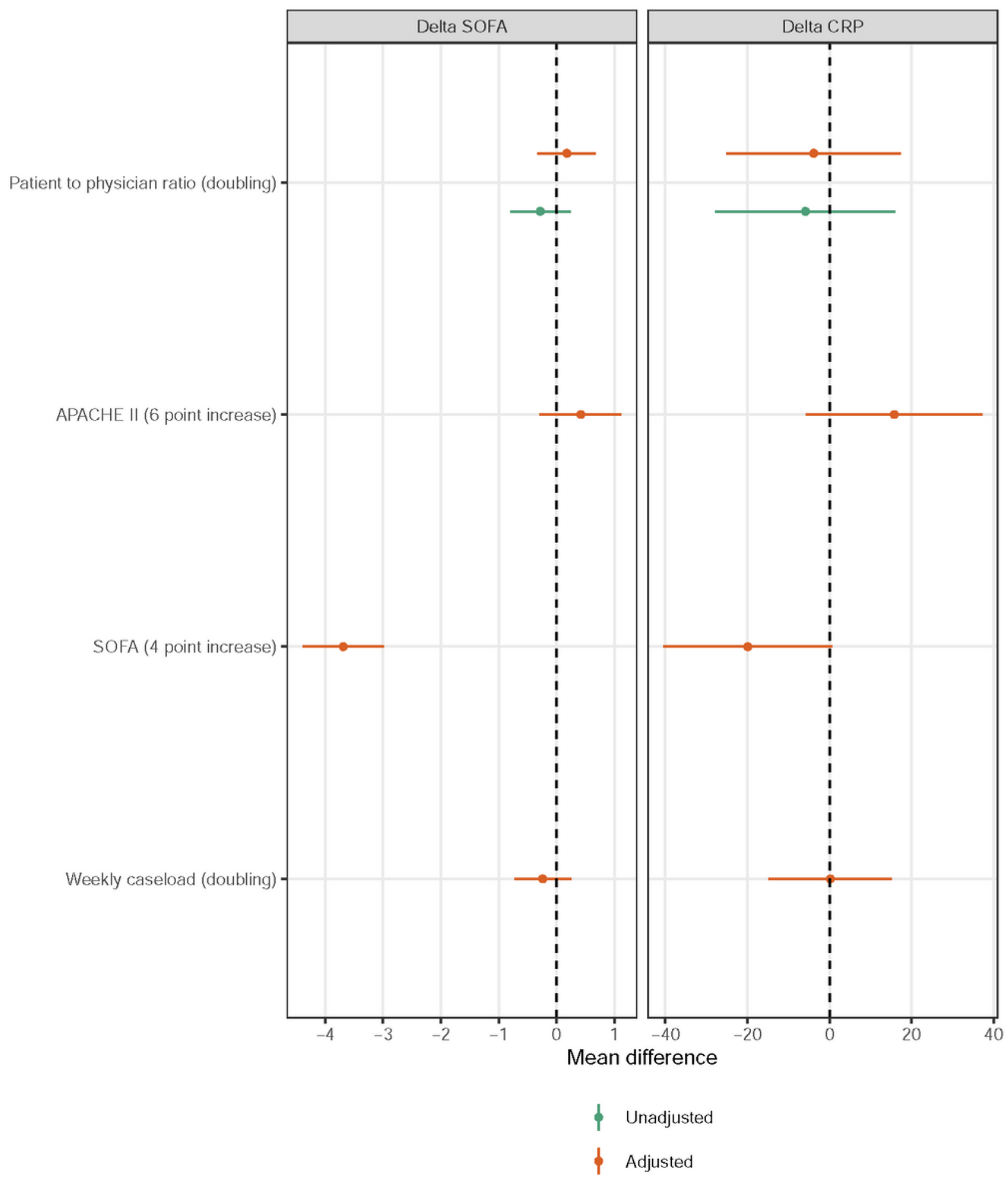

Figure 6

Patient-to-physician ratio and Delta SOFA, Delta CRP Notes: APACHE II = Acute Physiology and Chronic Health Evaluation II, SOFA = Sequential Organ Failure Assessment

\section{Supplementary Files}


This is a list of supplementary files associated with this preprint. Click to download.

- Supplemental1Table225082021.docx

- Supplement225082021.pdf 